
Table 1. The Effect of Ultra-vionigt on the Respiration-Rates
of Tobacco Leaves

Means over $10 \mathrm{hr}$. in mgm. $\mathrm{CO}_{2} / \mathrm{hr}$./gm. dry matter

\begin{tabular}{|c|c|c|}
\hline Exposure & Respiration & $\frac{\text { Irradiated }}{\text { Non-irradiated }}$ \\
\hline $\begin{array}{l}0 \\
1 \text { min. } \\
2 \text { min. } \\
3 \text { min. } \\
\text { S.E. }\end{array}$ & $\begin{array}{c}4 \cdot 15 \\
4 \cdot 20 \\
4 \cdot 28 \\
4 \cdot 63 \\
\pm 0 \cdot 257 \\
\text { No. of determinations represented by means }\end{array}$ & $\begin{array}{l}1 \cdot 01 \\
1 \cdot 03 \\
1 \cdot 11 \\
=8\end{array}$ \\
\hline $\begin{array}{l}0 \\
4 \text { min. } \\
\text { S. . }\end{array}$ & $\begin{array}{c}3 \cdot 48 \\
4 \cdot 14 \\
\pm 0 \cdot 206 \\
\text { No. of determinations represented by means }\end{array}$ & $\begin{aligned} & 1 \cdot 19 \\
= & 10\end{aligned}$ \\
\hline
\end{tabular}

dioxide analyser. Table 1 shows that the respirationrates increased with increasing exposure time, until, after $4 \mathrm{~min}$. exposure, the rates were increased by 20 per cent above the respiration-rates of comparable non-irradiated leaves.

To test whether this effect was reversed by visible light, leaves were irradiated for 5 min., and then half of them were kept in the dark for $2 \mathrm{hr}$. while half were exposed to full sunlight in a glasshouse. A similar number of non-irradiated leaves were given the same treatments as controls. Respiration measurements were begun at the end of the $2 \mathrm{hr}$. period, each experimental run involving the comparison of the respiration-rates of four leaves from each of the four treatments, over the same 10 hours. Table 2 shows that the respiration-rates of leaves irradiated and then kept in the dark were again 20 per cent higher than rates for non-irradiated leaves also kept in the dark, but the rates for irradiated leaves exposed to sunlight were not significantly higher than those of non-irradiated leaves which had also been exposed to sunlight.

Table 2. THE EFFECT OF Exposure TO VISIBLA LIGHT FOR 2 HR. ON THE RESPIRATION OF TOBACCO LEAVES AFTER IRRADIATION WITH UATRA-VIOLET FOR 5 MIN.

Means over $10 \mathrm{hr}$. in $\mathrm{mgm} . / \mathrm{CO}_{2} / \mathrm{hr}$./gm. dry matter Treatment after irradiation

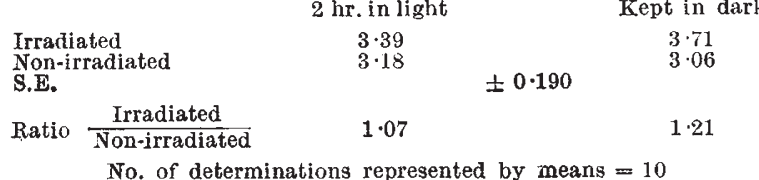

Bawden and Kleczkowski suggest that changes in leaf-cell components caused by ultra-violet radiation are reversed by visible light, or that light stimulates synthetic mechanisms to produce new components to replace those damaged. The latter suggestion now seems unlikely, because increased respiration would be expected to accompany such increased metabolic activity and no increase in respiration-rate was observed. Ultra-violet radiation must initiate a process or processes which is capable of proceeding in the absence of ultra-violet, as the effect of the disturbance to cell metabolism is still detectable $10 \mathrm{hr}$. after irradiation, but darkness is necessary for the reaction to proceed.

Infection with tobacco mosaic virus increases the respiration-rates of tobacco leaves immediately after inoculation ${ }^{2}$, and ultra-violet irradiation increases the respiration-rate immediately after treatment, the latter increase being four times the former. If both effects were due to action on the same cell component, the more rapid rates of change indicated by the larger energy expenditure after irradiation may mean that reduced supply of this component is responsible for the prevention of virus synthesis in irradiated leaves. The mechanism by which visible light counteracts this effect remains obscure. Rothamsted Experimental Station,
Harpenden, Herts.

P. C. OWEN

1 Bawden, F. C., and Kleczkowski, A., Nature, 169, 90 (1952).

2 Owen, P. C., Ann. Appl. Biol., 43, 114 (1955).

\section{Rapid Estimation of the Areas of the Leaves of Crop Plants}

For the physiological analysis of plant growth, estimates of the total leaf area per plant are required, and this may involve the determination of the areas of large numbers of leaves. Freeman and Bolas ${ }^{1}$ have described a method for the construction of a measuring grid from which the areas of leaves may be read directly, providing that the leaf-shape approximates closely to an ellipse, as does the shape of the apple leaves used by them.

It has been found possible to modify this method for use on leaves which are not elliptical, and a satisfactory grid has been constructed for sugar beet leaves. Further modification is possible for any leaves for which there exists a convenient pair of dimensions linearly related to area, and in which the leaf shape

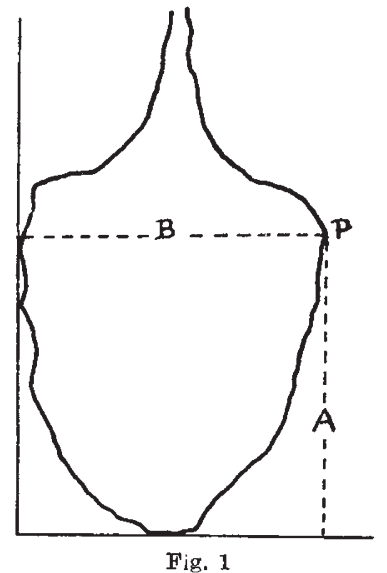

For sugar-beet leaves, a linear regression of leaf area on $A B$ accounted for 99 per cent of the variance of leaf area (regression coefficient $=b=1 \cdot 05 \pm 0 \cdot 013$ ). The leaf area is therefore equal to $b(A B)$. The co-ordinates of $P$ are $A, B$, and the area represented by the point is $A B$ units. Therefore, for $P$ to indicate the leaf area in sq.cm. on a grid constructed in the manner described by Freeman and Bolas, the area of each square of the grid must be $1 / b$ sq.cm. and the linear dimensions of the grid must be $\sqrt{1 / b} \mathrm{~cm}$. The grid constructed for sugar-beet leaves contained squares each of $0.97 \mathrm{~cm}$. sides, so the figure at point $P$ of each leaf placed on the grid represented the area of that leaf in sq.cm. To test the method the areas of 155 leaves were measured by the grid and by planimeter, the areas of the leaves varying from I to $400 \mathrm{sq} . \mathrm{cm}$. Linear regression of the planimeter areas against the grid areas accounted for $99 \cdot 2$ per cent of the variance of the areas. This method is likely to be more accurate than the must be estimated without destroying the leaves.

Rothamsted Experimental Station,

P. C. OWEN rating methods at present used when the leaf areas

1 Freeman, G. H., and Bolas, B. D., Rep. E. Malling Res. Sta. for $1955,104(1956)$. 